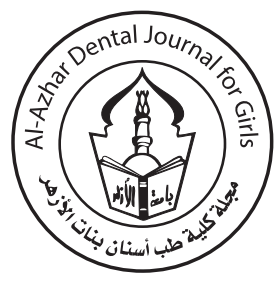

\title{
Influence of Coronal Preflaring on Apical Extrusion of Debris during Root Canal Preparation Using Two Reciprocating Single-File Systems
}

\author{
Yosra A. Mohamed ${ }^{1 *}$, Mohammed M. Khalefa ${ }^{2}$, Hagar A. Bastawy
}

Codex : 19/2001

azhardentj@azhar.edu.eg

http://adjg.journals.ekb.eg

DOI: $10.21608 /$ adjg.2019.9859.1127

\section{KEYWORDS}

Wave One Gold and Reciproc, Coronal preflaring, apically extruded debris.

\begin{abstract}
Purpose: The present study was designed to detect the effect of coronal preflaring on the amount of debris extrusion during canal preparation by reciprocating systems, WaveOne Golda nd Reciproc. Material and Methods: Sixty lower first molars having mesiobuccal canal curvature range between $25^{\circ}-35^{\circ}$ were used. They were divided into 2 experimental groups (I and II) according to the method of preparation of the root canal (30 samples each). Group I: Samples were prepared with coronal preflaring. Group II: Samples were prepared without coronal preflaring. The experimental groups were classified into 2 subgroups (A,B) according to the reciprocating single-file system used (15 samples each). Subgroup A:Samples were instrumented using Reciproc file. Subgroup B: Samples were instrumented using WaveOne Gold file. The samples were mounted in a model to measure the amount of debris extrusion. Results: In Reciproc subgroup, no statistical difference was found in samples prepared with and without coronal preflaring regarding the median of debris extrusion( $\mathrm{P}>0$.05).In WaveOne Gold subgroup, samples prepared with coronal preflaring showed lower value of apically extruded debris than samples prepared without coronal preflaring. However, no statistical difference was found between the tested samples in the median of debris extrusion $(\mathrm{P}>0.05)$.In group I and II: (with and without coronal preflaring respectively), no significant difference was found between Reciproc and WaveOne Gold in the median of debris extruded apically (P> 0.05). Conclusions: During preparation of the canal WaveOne Gold and Reciproc reciprocating single-file systems presented similar behavior regarding the amount of debris extrusion.During canal preparation coronal preflaring has no effect on the amount of debris extrusion using reciprocating systems, Wave One Gold and Reciproc.
\end{abstract}

- Paper extracted from Master thesis titled "Influence of Coronal Preflaring on Apical Extrusion of Debris during Root Canal Preparation Using Two Reciprocating Single-File Systems".

1. Dentist at Ministry of Health.

2. Professor of Endodontics, Endodontic Department, Faculty of Dental Medicine for Girls, Al-Azhar University.

3. Associate Professor of Endodontics, Department of Endodontics, Faculty of Dentistry, King Abdulaziz University(KAU), Jeddah, Saudi Arabiaand Endodontic Department, Faculty of Dental Medicine for Girls, Al-Azhar University, Cairo, Egypt.

* Corresponding author Email: yosraahmed3591@gmail.com 


\section{INTRODUCTION}

Shaping and cleaning of the canal is a very important procedure in root canal therapy. Cleaning is important in clearing pulp remnants and the infected part of dentin from the canals, while shaping enlarge the root canal system for easily placement of a root canal filling ${ }^{(1,2)}$.Nickel-titanium (Ni-Ti instruments have become indispensable, due to their greater flexibility and super-elasticity, resulted in improved shaping of the canal and decreased transportation. Although, fracture by cyclic fatigue is still present in $\mathrm{Ni}-\mathrm{Ti}$ instruments ${ }^{(3-9)}$.

With technological advancements in movement kinematics, a new reciprocating $\mathrm{Ni}-\mathrm{Ti}$ instrument has been introduced ${ }^{(10)}$, and new instruments in reciprocating motion were used; Reciproc, WaveOne and WaveOne Gold. The direction of cutting of these instruments is $\mathrm{CCW}$, soif the $\mathrm{CW}$ movement was smaller than the $\mathrm{CCW}$ movement the instruments can cut ${ }^{(11-13)}$.

Extrusion of irrigating solutions and debris contain microorganisms, dentin particles, and pulpal fragments during canal preparation may occur. These extruded elements can cause inflammation, flare-ups, and failure ${ }^{(14)}$. It was concluded that by many studies all instruments and preparation techniques extruded debris apically ${ }^{(15-18)}$. Although, the possibility of debris extrusion during preparation of the canal in reciprocating instruments is greater than those obtained with rotary instruments ${ }^{(19-22)}$. Therefore, methods to minimize this phenomenon are continuously investigated.

For debris collection in the coronal portion of the canal a reservoir can be created by coronal preflaring. Therefore, making coronal preflaring before canal instrumentation, make the coronal part large for debris removal ${ }^{(23)}$. Moreover, it has been concluded that irrespective of the preparation technique used coronal preflaring led to smaller amounts of debris extruded apically ${ }^{(24)}$.
It has been concluded that more significantly debris was extruded by the Reciproc system than the WaveOne system ${ }^{(25,26)}$. Moreover, the Wave One Gold extruded less amount of debris than Reciproc. One Shape and F360 files ${ }^{(27)}$. On the Other hand, it has been demonstrated that compared to Reciproc system WaveOne had more apical debris extrusion ${ }^{(28)}$.In previous studies, it has been reported that no significant difference between WaveOne and Reciproc $^{(29)}$, or Reciproc, One Shape and Wave One instruments ${ }^{(30)}$.

Apical debris extrusion has been demonstrated to vary based on files number, shape of the file system, movement kinematics and coronal preflaring. Therefore, the current study was directed to detect the influence of coronal preflaring on debris extrusion during preparation of the canal by single reciprocating file systems; WaveOne Gold and Reciproc.

\section{MATERIAL and METHODS}

\section{Samples preparation and selection:}

Sixty lower first molars with mesial roots having 2 separate mesial canals and apical foramina, an average length of 15 to $16 \mathrm{~mm}$, were extracted and selected. The mesiobuccal canal curvature ranged between $25^{\circ}-35^{\circ}$ according to Schneider technique ${ }^{(31)}$ and standardized apical foramen diameter to \# 10 $\mathrm{K}$-file. In accordance with guidelines of Research Ethics Committee (REC) of Al-Azhar University, Faculty of Dental Medicine for Girls, ethical approval for the use of extracted teeth of human were obtained.

Using diamond disc all crowns were decapitated at the cemento-enamel junction using constant water cooling to have the same root length $(15-16 \mathrm{~mm})$. The distal root of each sample was resected at the level of the furcation with a tapered diamond stone in a high-speed handpiece. 


\section{Determination of root canal curvature:}

The samples were placed in plastic dental arches that used as a holder to ensure samples stability during scanning. Radiographs were taken for each sample in the clinical view by using \# $10 \mathrm{~K}$-file in mesiobuccal canal adjusted to apical foramen, using an image plate of indirect digital radiography with Orix X-ray machine (ARDET Srl, Italy) at 60 Kilovolt, $10 \mathrm{~mA}$ for 0.04 seconds exposure time. The flatbed scanner was used and the image plate was inserted into it and within seconds on the computer screen the radiographic image was displaced and saved.

To determine the angle of curvature by using Vista Scan System (DBS-WIN Software),Schneider's technique was used. Through the coronal straight part of the canal, a straight line (a) was drawn and from the apical foramen a second line (b) was drawn to make intersection in the point where the first line left the long axis of the canal. The intersection of the two lines form the angle $(\alpha)$ and it was measured as the canal curvature. In each sample, the root canal curvature was drawn three times, where the distance of the second line was fixed in each time to ensure reproducible measurement and then the mean of the three values was calculated.

\section{Debris extrusion model:}

To evaluate the extrusion of debris the samples were mounted in experimental model ${ }^{(25)}$. On the Eppendorf tube cap a hole was created and the sample was placed up to the cemento-enamel junction. To make the pressure of the air outside and inside the Eppendorf tubes equal needle with25-G was placed through the cap for drainage. Then, the needle and the root in each cap was inserted to its Eppendorf tube which was fixed to vials surrounded with aluminum foil to not allow seeing debris extruded during instrumentation.

The whole apparatus was used only by the vial. By using a microbalance, to $10-5$ precision the Eppendorf tubes were weighed before canal instrumentation, three consecutive measurements was taken to record the mean value for each Eppendorf tube.

\section{Samplesgrouping and root canal instrumentation:}

Samples were classified into 2 experimental groups (I and II) according to the method of root canal preparation used (30 samples each):

Group I: Samples were prepared with coronal preflaring using \# 3,\#2 and \#1 Gates Glidden drills respectively, where Gates Glidden drill \# 3 used to a depth $1 \mathrm{~mm}$, followed by \#2 to depth 2 mmand \# 1 used to depth $3 \mathrm{~mm}$, then the canals were irrigated with distilled water.

Group II: Samples were prepared without coronal preflaring.

Each experimental group was classified into 2 subgroups (A and B) according to reciprocating single-file system used in root canal instrumentation (15 samples each):

\section{Subgroup A: (Reciproc):}

The Reciproc R25 file (\# 25/0.08 taper) was used according to the manufacture recommendations. The Reciproc file was adjusted to $2 / 3$ of the working length (WL) and inserted with a slow pecking motion in-and-out into the canal without removing the instrument totally from the canal. The in-and out-movements did not be more than 3-4 mm. The instrument was removed from the canal after three in-and out-movements to clean the flutes. For irrigation distilled water was used, and then the file was re-used in the same manner until the correct working length was reached.

\section{Subgroup B: (WaveOne Gold):}

The WaveOne Gold Primary file (\# 25/0.07 taper) was used according to manufacture recommendations. After creating a glide path, the Primary file 
was inserted and the rubber stopper was adjusted to the reference point to detect the initial file penetration depth. The file was passively advanced downward into the canal upon activation of the reciprocating motor and in the presence of irrigation solution (distilled water).

After 2 in-and-out-movements (pecks) the instrument's flutes were cleaned to enhance debris removal. After each step, the instruments were inspected for any distortion before using the instrument again. Before using the instrument again any compacted debris should be cleared from the root canal. The next cutting cycle was performed to reach the full WL.

With $10 \mathrm{ml}$ of distilled water dispensed through a 31-gauge side vent irrigating needle, canal irrigation was done after instrumentation; the needle was inserted $2 \mathrm{~mm}$ shorter than the working length without binding. Four root canals could be prepared by only one file. Finally, each sample will be flushed with distilled water in order to clear any debris present inthe outerpart of the apex.

\section{Evaluation of apically extruded debris:}

The Eppendorf tubes were taken away from the vials at the end of the canal preparation. One $\mathrm{ml}$ distilled water was used to wash and collect the debris present in outer surface of the apex. Before measuring the dry debris an incubator at $37{ }^{\circ} \mathrm{C}$ for 15 days was used to evaporate the distilled water ${ }^{(15)}$. With a difference of $<0.00002 \mathrm{~g}$ for each tube three consecutive weights was taken, to calculate the mean value. The empty Eppendorf tube original weight was subtracted from the gross weight to determine the net weight of the dry debris.

\section{Statistical analysis:}

The distribution of data was checked by the tests of normality (Kolmogorov-Smirnov and Shapiro-
Wilk tests). Data gave non-parametric distribution. Data were showed as median, minimum and maximum values. To compare between the two systems as well as to study the effect of coronal flaring Mann-Whitney U test was used. To know the difference between the four groups KruskalWallis test was used. When Kruskal-Wallis test is significant Dunn's test was used for pair-wise comparisons. The significance level was set at $\mathrm{P} \leq$ 0.05 . Statistical analysis was performed with IBM, SPSS Statistics Version 20 for Windows.

\section{RESULTS}

\section{Differences in the amount of debris extrusion within each subgroup:(Table 1) and (Fig. 1)}

\section{a. Subgroup (A) (Reciproc):}

The minimum, maximum and median of debris extruded apically of group I (with coronal preflaring) and group II (without coronal preflaring) were $(0.0011,0.0070$ and 0.0023$)$ and $(0.0013$, 0.0047 and 0.0023 ) respectively. Mann-Whitney $\mathrm{U}$ test proved that, no statistical variables was found between samples prepared with and without coronal preflaring in the median of debris extrusion $(\mathrm{P}>0.05)$.

\section{b. Subgroup (B) (WaveOne Gold):}

The minimum, maximum and median of apically extruded debris of group I (with coronal preflaring) and group II (without coronal preflaring) were $(0.0011,0.0057$ and 0.0019$)$ and $(0.0014,0.0039$ and 0.0023 ) respectively. The results revealed that, samples prepared with coronal preflaring showed lower value of apically extruded debris than samples prepared without coronal preflaring. However, Mann-Whitney U test showed that, no statistically significant variables was found between the tested groups in the median of debris extrusion $(\mathrm{P}>0.05)$. 
Table (1): The minimum, maximum and median of debris extruded apically with and without coronal preflaring within each subgroup.

\begin{tabular}{|c|c|c|c|c|c|c|c|}
\hline \multirow{2}{*}{ Instrument } & \multicolumn{3}{|c|}{$\begin{array}{c}\text { Group I } \\
\text { (With coronal preflaring) }\end{array}$} & \multicolumn{3}{c|}{ Group II } \\
(Without coronal preflaring) & \multirow{2}{*}{ P-value } \\
\cline { 2 - 7 } & Minimum & mMaximu & Median & Minimum & Maximum & Median & \\
\hline $\begin{array}{c}\text { Subgroup A } \\
\text { (Reciproc) }\end{array}$ & 0.0011 & 0.0070 & 0.0023 & 0.0013 & 0.0047 & 0.0023 & 0.853 \\
\hline $\begin{array}{c}\text { Subgroup B } \\
\text { (WaveOne Gold) }\end{array}$ & 0.0011 & 0.0057 & 0.0019 & 0.0014 & 0.0039 & 0.0023 & 0.426 \\
\hline
\end{tabular}

*: Significant at $P \leq 0.05$

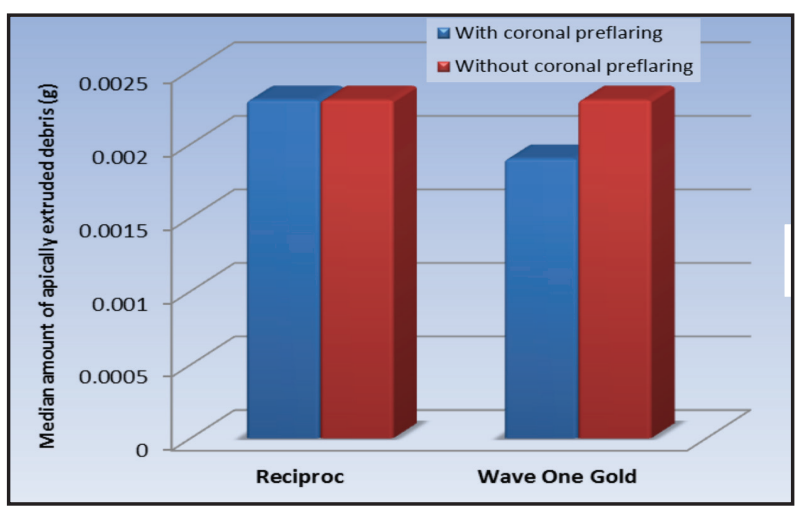

Figure (1) A bar chart comparing the median of debris extruded apically with and without coronal preflaring within each subgroup.

Comparison in debris extrusion between the two instruments: (Table 2) and (Fig. 2)

\section{a. Group I: (With coronal preflaring):}

The minimum, maximum and median of apically extruded debris of subgroup A (Reciproc) and subgroup B (Wave One Gold) were (0.0011, 0.0070 and 0.0023$)$ and $(0.0011,0.0057$ and 0.0019$)$ respectively. The results revealed that, samples prepared with WaveOne Gold showed lower value of apically extruded debris than samples prepared with Reciproc. However, Mann-Whitney U test proved that, no statistically significant variables was found between the tested instruments in the median of debris extruded apically $(\mathrm{P}>0.05)$.

\section{b. Group II: (Without coronal preflaring):}

The minimum, maximum and median of apically extruded debris of subgroup A (Reciproc) and subgroup B (WaveOne Gold) were (0.0013, 0.0047 and 0.0023$)$ and $(0.0014,0.0039$ and 0.0023 ) respectively. Mann-Whitney U test proved that, no statistical variables was found between the tested instruments in the median of debris extrusion $(\mathrm{P}>0.05)$.

Table (2): The minimum, maximum and median of apically extruded debris comparing the tested instruments within each group.

\begin{tabular}{|c|c|c|c|c|c|c|c|}
\hline \multirow{2}{*}{ Instrument } & \multicolumn{3}{|c|}{$\begin{array}{l}\text { Subgroup A } \\
\text { (Reciproc) }\end{array}$} & \multicolumn{3}{|c|}{$\begin{array}{c}\text { Subgroup B } \\
\text { (WaveOne Gold) }\end{array}$} & \multirow{2}{*}{ P-value } \\
\hline & Minimum & Maximum & Median & Minimum & Maximum & Median & \\
\hline $\begin{array}{c}\text { Group I } \\
\text { (With coronal preflaring) }\end{array}$ & 0.0011 & 0.0070 & 0.0023 & 0.0011 & 0.0057 & 0.0019 & 0.426 \\
\hline $\begin{array}{c}\text { Group II } \\
\text { (Without coronal } \\
\text { preflaring) }\end{array}$ & 0.0013 & 0.0047 & 0.0023 & 0.0014 & 0.0039 & 0.0023 & 0.912 \\
\hline
\end{tabular}

*: Significant at $P \leq 0.05$ 


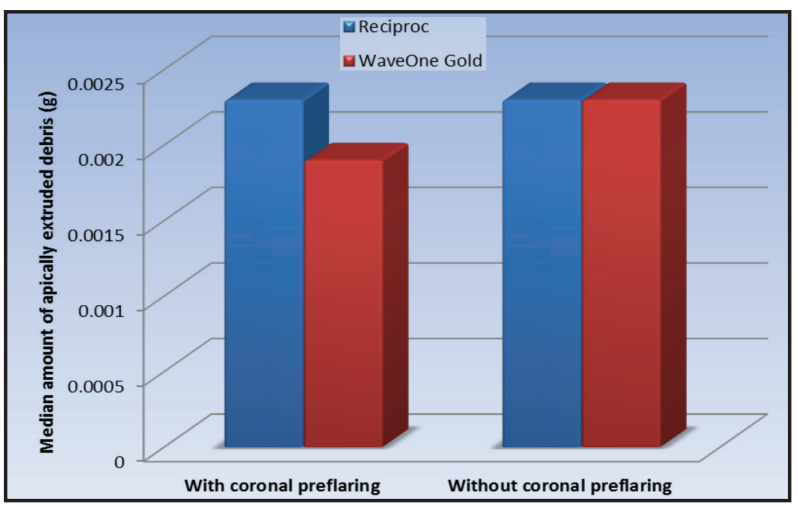

Figure (2) A bar chart comparing the median of debris extrusion between the tested instruments within each group.

\section{DISCUSSION}

Dentin chips, irrigants, microorganisms and remaining pulpal tissues can be escaped into periapical tissues when the root canal was prepared despite the correct length of the work. Undesired consequences, like pain after treatment, delay the healing apically and inflammation may cause due to escape of these elements into periapical tissues ${ }^{(32,33)}$. In the present time none of instruments or preparation techniques are not causing debris extrusion ${ }^{(15,34)}$; however, quantity of debris may be different according to the design of the file and endodontic instruments kinematics ${ }^{(16,29)}$.

Recently a new Ni-Ti reciprocating instruments has been introduced ${ }^{(10)}$.The number of cycles of the instrument would be reduced due to the alternating changes in direction of rotation and therefore, decrease the instrument cyclic fatigue compared to instruments with a consistent rotating motion ${ }^{(35,36)}$. Also these instruments decrease files needed and the steps number while still allowing a good cleaning and preparation of the root canal ${ }^{(37)}$. However, there are conflicting results regarding the debris extrusion during preparation the canal with reciprocating systems. ${ }^{(19-22)}$.

The clinical technique in which reciprocating instruments like WaveOne Gold and Reciproc are used can have a large effect in the successful outcome of the cleaning and preparation phase of endodontic treatment. The reciprocating movement has many advantages compared to instruments that are used in a consistent rotating motion ${ }^{(38)}$.

Coronal preflaring is used in the root canal orifice to remove cervical interferences which cause a problem in the instrumentation of the canals ${ }^{(39)}$. To permit the file preparing the apical part in less friction and less contact in the wall and facilitates the access for irrigants coronal preflaring is used ${ }^{(40,41)}$. The reciprocating systems used do not have a coronal flaring instrument so Gates-Glidden drills were used.

Between different systems differences in extrusion of debris have also been observed. It related to cutting blade, the taper, tip design, flexibility, and the cross section and also, cutting efficacy, number of files and concepts of use. Therefore, the aim of the present study was directed to detect the influence of coronal preflaring on the quantity of debris extrusion while preparation of the canal by two reciprocating systems; Wave One Gold and Reciproc.

In the current study extracted first lower molars with the mesiobuccal root canals curvature range between $25^{\circ}-35^{\circ}$ were used according to Schneider's technique ${ }^{(31)}$ due to their anatomical characteristics, where most of them are narrow and curved ${ }^{(42)}$.

The most common endodontic complexity is the curved canals ${ }^{(43)}$.In the larger and straight canals lot of techniques and methods of canal preparation work well. However, the complexity of the case increases markedly when the curvature of the canal reaches 30 degrees or more and in the simpler cases the techniques that give good results may or may not be successful ${ }^{(44)}$.

To measure the debris extruded apically, different techniques are used. In this study, the technique which was used to collect and quantified the amount of debris extruded to the apex is easier than other methods ${ }^{(25)}$. 
To prevent sodium hypochlorite from making crystals, irrigation with distilled water was used, because the crystals that still present cannot be detached from the debris after the irrigation solution evaporate. These may change the results ${ }^{(45,14)}$.To prevent debris extrusion to the apex by anything different from the instrumentation system used, the irrigating needle was used passively without binding

In the current study, the length of the work was adjusted $1 \mathrm{~mm}$ short of the apex, where it has been reported that significantly less debris extrusion was contributed to adjusting the length of the work $1 \mathrm{~mm}$ before the apex ${ }^{(46-48)}$.

No statistical difference was found in Reciproc system between Reciproc with coronal preflaring and Reciproc without coronal preflaring in the quantity of extrusion. This could be with reason that, centering ability associated with reciprocation and the cutting efficiency of the Reciproc instruments allows the enlargement of narrow and un-instrumented canals in a safe manner without coronal preflaring. Moreover, the Reciproc instrument used in the lateral walls in a brushing motion making the same action of coronal preflaring with Gates Glidden drills ${ }^{(49)}$.

These results were in disagreement with other study which reported that, using Reciproc file without coronal preflaring produced significantly more debris in comparison to Reciproc file used with coronal preflaring ${ }^{(23)}$. This divergence in results could be explained by using different teeth (single rooted mandibular incisors).

In Wave One Gold system, the canals prepared with coronal preflaring produced less apically extruded debris compared to those prepared without coronal preflaring. However, no significant variables were found between Wave One Gold with coronal preflaring and Wave One Gold without coronal preflaring in the amount of debris extrusion. This could be due to creation of debris container to collect of debris in the coronal part of the canal by coronal preflaring, as debris were directed coronally by Ni-Ti instruments ${ }^{(50)}$. Therefore, the amount of debris extrusion may reduce by increasing the coronal part for debris.

These results were in agreement with other study which stated that, the amount of debris extrusion was reduced by coronal preflaring when compared to no coronal preflaring using two reciprocating singlefile systems. Moreover, another study stated that, the amount of debris extrusion was reduced when using reciprocating single-file systems after making coronal preflaring before canal preparation ${ }^{(23,24)}$.

In group I (with coronal preflaring), the use of Wave One Gold system produced lower value of apically extruded debris compared to Reciproc system. However, no significant difference was observed between WaveOne Gold and Reciproc systems in the median of debris extrusion.

These results could be due to the cross-section of the WaveOne Gold instrument which is a parallelogram with two 85-degree cutting edges in touch with the walls of the canal, changing with a patented off-centered cross section where only one cutting edge is in touch with the walls of the canal that allow additional space around the instrument. Therefore might provide space for debris accumulation and coronal removal of debris (51). Furthermore, Wave One GOLD decrease the mass at the center of the tip as its tip is tapered and modified, therefore improves its penetration into any canal eliminating the need to push on the file, and thereby promoting minimal apical extrusion ${ }^{(52)}$.

These results were in agreement with a recent study which revealed that, maximum amount of debris extruded by Reciproc while Wave One Gold system resulted in smallest quantity of debris extrusion in comparison with WaveOne Gold, One Shape and F360 file systems ${ }^{(27)}$.

In group II (without coronal preflaring), no significant variables was found between Reciproc and Wave One Gold systems in the median of debris extrusion. These can be due to the design of 
the cross-sectional of Wave One Gold and Reciproc systems, where, the constant taper in the first $3 \mathrm{~mm}$ of the working part that descends to D16 and the S-shape cross-section of Reciproc instrument along the entire length of the working part might favor better removal of debris in coronal direction (26). Moreover, the additional space around Wave One Gold instrument might provide space for coronal debris removal ${ }^{(51)}$.

These results were inconsistent with other study which detected that smallest quantity of periapical debris extrusion was resulted by Wave One Gold, while maximum amount of debris was resulted by Reciproc, when compared with Wave One Gold, One Shape and F360 file systems. This divergence in results could be explained by using different teeth (straight single canals) ${ }^{(27)}$.

\section{CONCLUSIONS}

1. Reciproc and WaveOne Gold reciprocating single-file systems presented similar behavior during preparation of the root canal regarding the quantity of debris extrusion.

2. Coronal preflaring has no impact on the quantity of debris extrusion using Reciproc and Wave One Gold reciprocating systems while preparation of the canal.

\section{REFERENCES}

1. Schilder H. Cleaning and shaping the root canals. Dent. Clin. North Am 1974; 18:269-96.

2. Alodeh MHA, Doller R, Dummer PMH. Shaping of simulated root canalsin resin blocks using the stepbacktechnique with K-files manipulated in asimple in/our filling motion. IntEndod J 1989; 22: 107-17.

3. Esposito PT and Cunningham CJ. A comparison of canal preparation with nickel-titanium and stainless-steel instruments. J Endod 1995; 21: 173-6.

4. Gambill JM, Alder M, Del Rio CE. Comparison of nickeltitanium and stainless-steel hand-file instrumentation using computed tomography. J Endod1996; 22: 369-75.
5. Pettiette MT, Metzger Z, Phillips C, Trope M. Endodontic complications of root canal therapy performed by dental students with stainless steel K-files and nickel-titanium hand files. J Endod 1999; 25: 230-4.

6. Thompson SA. An overview of nickel-titanium used in dentistry. IntEndod J 2000; 33: 297-310.

7. Glosson CR, Haller RH, Dove SB, Del Rio CE. A comparison of root canal preparations using $\mathrm{Ni}-\mathrm{Ti}$ hand, $\mathrm{Ni}$-Ti engine-driven, and K-Flex endodontic instruments. J Endod 1995; 21: 146-51.

8. Park H. A comparison of greater taper files, profiles, and stainless-steel files to shape curved root canals. Oral Surg Oral Med Oral Pathol Oral RadiolEndod2001; 9:715-8.

9. Pruett JP, Clement DJ, Carnes DL. Cyclic fatigue testing of nickel-titanium endodontic instruments. J Endod 1997; 23: 77-85.

10. Yared G. Canal preparation using only one Ni-Ti rotary instrument: preliminary observations. IntEndod J 2008; 41: 339-44.

11. Webber J, Machtou P, Pertot W, Kuttler S, Ruddle C, West J. The WaveOne single-file reciprocating system. Roots 2011; 1: 28-33.

12. Bürklein S, Hinschitza K, Dammaschke T, Schäfer E. Shaping ability and cleaning effectiveness of two singlefile systems in severely curved root canals of extracted teeth: Reciproc and WaveOne versus Mtwo and ProTaper. IntEndod J 2012; 45: 449-61.

13. Webber J. Shaping canals with confidence: WaveOne GOLD single-file reciprocating system. Roots 2015; 1:3440.

14. Tanalp $\mathbf{J}$ and Gungor T. Apical extrusion of debris: a literature review of an inherent occurrence during root canal treatment. IntEndod J 2014; 47:211-21.

15. Kocak S, Kocak MM, Saglam BC, Turker SA, Sagsen B, Er O. Apical extrusion of debris using self-adjusting file, reciprocating single-file, and 2 rotary instrumentation systems. J Endod 2013; 39:1278-80.

16. Capar ID, Arslan H, Akcay M, Ertas H. An in vitro comparison of apically extruded debris and instrumentation times with ProTaper Universal, ProTaper Next, Twisted File Adaptive, and HyFlex instruments. J Endod 2014; 40:1638-41.

17. Ozsu D, Karatas E, Arslan H, Topcu MC. Quantitative evaluation of apically extruded debris during root canal instrumentation with ProTaperUniversal, ProTaper Next, 
WaveOne, and self-adjusting file systems. Eur J Dent 2014; 8:504-8.

18. Ustun Y, Canakci BC, Dincer AN, Er O, Duzgun S. Evaluation of apically extruded debris associated with several Ni-Ti systems. IntEndod J 2015; 48:701-4.

19. De-Deus G, Brandão MC, Barino B, Di Giorgi K, Fidel RA, Luna AS. Assessment of apically extruded debris produced by the single-file ProTaper F2 technique under reciprocating movement. Oral Surg Oral Med Oral Pathol Oral RadiolEndod2010; 110: 390-4.

20. Hussein HM and Al-Zaka IM. Evaluation of the amount of apically extruded debris using different root canal instrumentation systems. MDJ 2014; 11:1-10.

21. Nevares G, Xavier F, Gominho L, CavalcantiF,Cassimiro M, Romeiro K et al. Apical Extrusion of Debris Produced during Continuous Rotating and Reciprocating Motion. Sci World J 2015; 20:1-5.

22. Vivekanandhan P, Subbiya A, Mitthra S, Karthick A. Comparison of apical debris extrusion of two rotary systems and one reciprocating system. J Conserv Dent 2016; 19:245-9.

23. Topçuoğlu HS, Üstün Y, Akpek F, Aktı A, Topçuoğlu G. Effect of coronal flaring on apical extrusion of debris during root canal instrumentation using single-file systems. IntEndod J 2016; 49:884-9.

24. Borges ÁH, Pereira TM, Porto AN, de Araújo Estrela CR, Miranda Pedro FL, et al . The influence of cervical preflaring on the amount of apically extruded debris after root canal preparation using different instrumentation systems. J Endod. 2016; 42:465-9.

25. Bürklein S and Schäfer E. Apically extruded debris with reciprocating single-file and full-sequence rotary instrumentation systems.JEndod 2012; 38:850-2.

26. Xavier F, Nevares G, Romeiro M. K, Gonçalves K, Gominho L, Albuquerque D. Apical extrusion of debris from root canalsusing reciprocating files associated with two irrigation systems. IntEndod J 2014; 48:661-5.

27. Tomer AK, Mangat P, Mullick S, Dubey S, Chauhan P, et al. Quantitative evaluation of apically extruded debris of different single file systems: Wave One Gold, One Shape, F360, and Reciproc: an in vitro study. IJOCR 2017; 5:1-3.

28. Uzun I, Guler B, Ozyurek T, Tunc T. Apical extrusion of debris using reciprocating files and rotary instrumentation systems. Niger J ClinPract 2016; 19:71-5.
29. De-Deus G, Neves A, Silva EJ, Mendonca TA, Lourenco C, Calixto C, et al. Apically extruded dentin debris by reciprocating single-file and multi-file rotary system. Clin Oral Investig 2015; 19:357-61.

30. Topçuoğlu HS, Düzgün S, Akpek F, Topçuoğlu G, Aktı A. Influence of a glide path on apical extrusion of debris during canal preparation using single-file systems in curved canals. IntEndod J 2015; 49:599-603.

31. Schneider SW. A Comparison of canal preparations in straight and curved root canals. Oral Surg Oral Med Oral Pathol Oral Radiol 1971; 32:271-5.

32. Seltzer S and Naidorf IJ. Flare-ups in endodontics: I. etiological factors. J Endod 1985; 11:472-8.

33. Siqueira JF Jr, Rocas IN, FavieriA,Machado AG, GahyvaSM,etal.Incidence of postoperative pain after intracanal procedures based on an antimicrobial strategy. $\mathrm{J}$ Endod 2002; 28:457-60.

34. De-Deus GA, Nogueira Leal Silva EJ, Moreira EJ, de Almeida NA, Belladonna FG, et al. Assessment of apically extruded debris produced by the self-adjusting file system. J Endod 2014; 40:526-9.

35. Varelo-Patino P, Ibanez-Párraga A, Rivas-Mundiña B, Cantatore G, Otero XL, et al.Alternating versus continuous rotation: a comparative study of the effect on instrument life. J Endod 2010; 36: 157-9.

36. You SY, Bae KS, Baek SH, Kum KY, Shon WJ, et al. Lifespan of one nickel-titanium rotary file with reciprocating motion in curved root canals. J Endod 2010; 36:1991-4.

37. Amaral P, Forner L, Llena C. Smear layer removal in canals shaped with reciprocating rotary systems. J ClinExp Dent 2013; 5:227-30.

38. Van der Vyver PJ and Jonker C. Reciprocating instruments in endodontics: a review of the literature. SADJ 2014; 69:404-9.

39. 39.Schmitz MS, Santos RE, Capelli A, Jacobovitz M, Spano JC, et al. Influence of cervical preflaring on determination of apical file size in mandibular molars: SEM analysis. BrazDent J2008; 19: 245-51.

40. Leeb J. Canal orifice enlargement as related to biomechanical preparation. J Endod 1983; 9: 463-70.

41. Peters OA and Paque F. Current developments in rotary root canal instrument technology and clinical use: a review. Quintessence Int 2010; 41: 479-88. 
42. De Pablo OV, Estevez R, Peix-Sanchez M, Heilborn C, Cohenca N. Root anatomy and canal configuration of the permanent mandibular first molar: a systematic review. JEndod 2010; 36:1919-31 .

43. Harper and Row. James W Clark; chapter in endodontics. Clark's Clinical dentistry 1998; 1.

44. Franklin S. Intracanal treatment procedures, basic and advanced topics.Endod therapy. Fifth Edition Mosby 1972:164-239.

45. Huang X, Ling J, Wei X, Gu L. Quantitative evaluation of debris extruded apically by using ProTaper Universal Tulsa rotary system in endodontic retreatment. J Endod 2007; 33:1102-5.

46. Martin H and Cunningham WT. The effect of endosonic and hand manipulation on the amount of root canal material extruded. Oral Surg Oral Med Oral Pathol 1982; 53:611-3.

47. Myers GL and Montgomery S. A comparison of weights of debris extruded apically by conventional filing and canal master techniques. J Endod 1991; 17:275-9.
48. Beeson TJ, Hartwell GR, Thornton JD, Gunsolley JC. Comparison of debris extruded apically in straight canals: conventional filing versus profile .04 Taper series 29. J Endod 1998; 24:18-22.

49. Yared G. Canal preparation using one reciprocating instrument without prior hand filing: a new concept. Int Dent SA - African Edition 2012; 2:78-87.

50. Imura N, Kato AS, Hata GI, Uemura M, Toda T, et al. A comparison of the relative efficacies of four hand and rotaryinstrumentation techniques during endodontic retreatment. IntEndod J 2000; 33:361-6.

51. Dincer AN, Guneser MB, Arslan D. Apical extrusion of debris during root canal preparation using a novel nickeltitanium file system: Wave One gold. J ConservDent 2017; 20:322-5.

52. Zan R, Topçuoğlu HS, HubbezoğluI, Tanalp J, Kazandağ MK. Evaluation of different instrumentation systems for apical extrusion of debris.7tepeklinik 2017; 10:1-7. 